\title{
IMPACT OF WALL SUPPORT CONDITIONS ON SEISMIC RESPONSE OF GROUND-SUPPORTED REINFORCED CONCRETE CONTAINMENT TANKS
}

\author{
NOOR SHARARI ${ }^{1}$, BEHZAD FATAHI $^{1} \&$ ASLAN S. HOKMABADI ${ }^{2}$ \\ ${ }^{1}$ School of Civil and Environmental Engineering, University of Technology Sydney, Australia \\ ${ }^{2}$ Arup, Sydney, Australia
}

\begin{abstract}
Concrete liquid storage tanks are commonly used in regions that may be highly seismic, for the storage of water, petroleum products and other chemicals. In some cases, such as for liquefied natural gas (LNG) tanks, a secondary concrete containment is designed for external protection, ignoring any direct contact or interaction with the inner storage liquid by creating a gap, as another inner tank is used to hold the liquid. Typical secondary containment tanks for LNG are circular, upright concrete tanks, with fixed roofs, while the support wall conditions at its base can be hinged or fixed. In this study, the nonlinear behavior of ground supported circular reinforced concrete containment tank under the effect of the seismic loads is investigated for both hinged and fixed wall support conditions. A threedimensional finite element model considering material nonlinearities was included. In particular, the Concrete Damage Plasticity (CDP) model, capturing the possible tensile cracking and compressive crushing of the concrete containment systems under seismic loads was adopted. By adopting time history analyses, deformation and stresses developed in the tank were assessed when subjected to large earthquakes, namely the 1994 Northridge and 1995 Kobe earthquakes, while frequency domain analyses were also conducted, to obtain the natural period and mode shapes for different wall support conditions. The results showed that in the hinged tank, the walls experience higher structural responses (in terms of shear force and bending moment); compared with the fixed tank, particularly around the mid-height zone of the tank wall. Conversely, at the base of the fixed tank, shear forces and bending moments were higher, compared with the hinged tank's base. Under the effects of large earthquakes, both tanks experienced damage, yet larger seismic forces upon a hinged tank could potentially create more damage.
\end{abstract}

Keywords: concrete construction, concrete containment, concrete damage, concrete plasticity, concrete wall, earthquake, liquid storage tanks, seismic damage, stiffness recovery, wall support.

\section{INTRODUCTION}

Ground supported concrete storage tanks are widely used for water, refined petroleum products, and chemicals; due to their large capacity and economic efficiency. These tanks may be used in regions with high seismicity; and therefore, assessing their seismic safety in those regions is essential.

For some cases, such as liquefied natural gas (LNG) tanks, a double-wall containment system is often used. Indeed, the natural gas is condensed to a liquid state by cooling it to a very low temperature (approximately $-168^{\circ} \mathrm{C}$ ) at atmospheric pressure [1]; thus, LNG needs to be stored in a primary inner steel tank to meet the ductility requirements of the tank, while the secondary outer tank is used for external protection [2]. The secondary containment tank is usually made of reinforced or pre-stressed concrete, without it having any direct contact or interaction with the stored liquid, in the normal conditions.

Most previous studies had focused on the seismic behaviour of the inner steel tank, considering the fluid-structure interaction; while studies on the secondary concrete containment tanks have been less popular [1]. Graczyk and Moan [3] studied the effect of the sloshing pressure on the LNG steel tank wall with different liquid levels. Christovasilis and 
Whittaker [4] studied the effectiveness of seismic base isolation on the performance of the LNG tanks and compared their results with a conventional tank. They conclude that the acceleration response reduced after using the base isolators, similar to the base shear and global overturning moment at the tank base. Some researchers had assessed the performance of the secondary concrete containment LNG tanks against external forces, such as a blast [5] or airplane impact [2].

This paper presents a rigorous three-dimensional (3D) nonlinear time history analysis of an empty ground-supported circular reinforced concrete containment tank, subjected to seismic action for hinged and fixed wall-to-base support conditions.

\section{DESCRIPTION OF LNG TANK}

A $30,000 \mathrm{~m}^{3}$ reinforced concrete outer LNG tank was adopted for this study. The tank is composed of a reinforced concrete roof, fixed to a wall that is sitting on a rigid foundation (Fig. 1). This LNG tank is an example of the modular LNG tanks that are used in highly seismic regions, as reported in the literature [6].

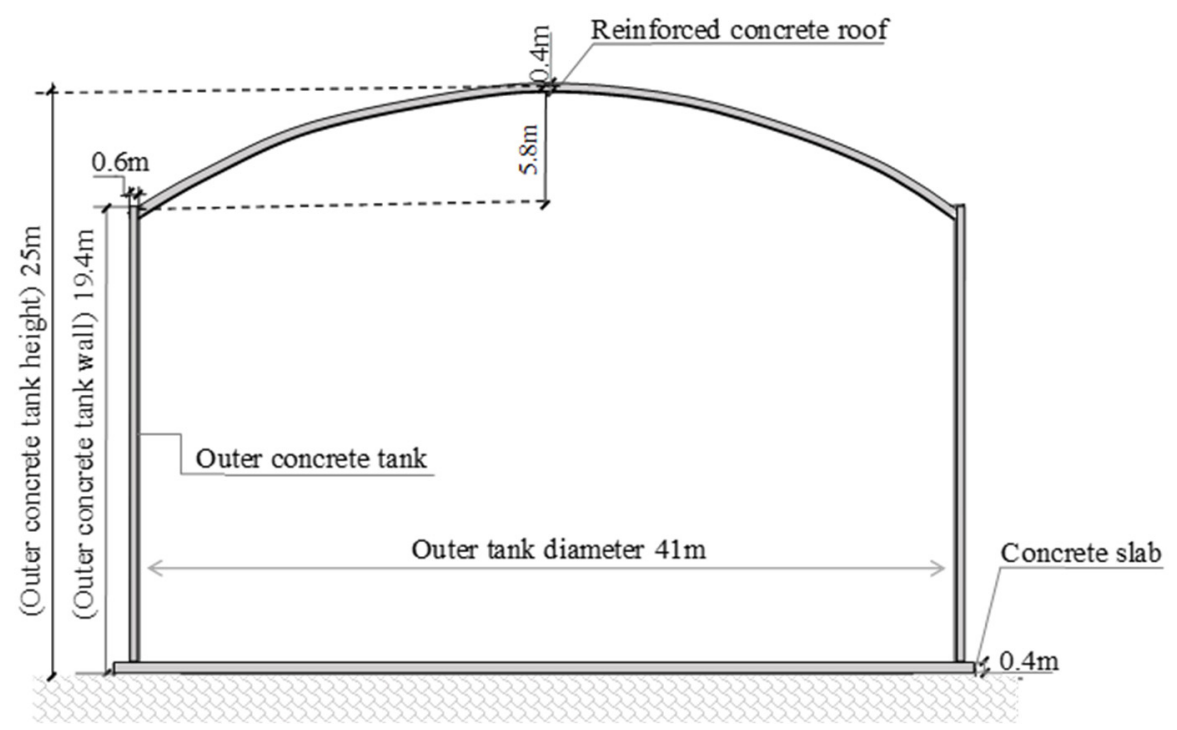

Figure 1: Schematic view of the adopted reinforced concrete outer tank for liquid nitrogen gas storage.

Because this study only investigates the effects of the wall at the foundation slab connection on the seismic behaviour of the concrete containment structure surrounding the LNG, only the outer tank with its roof and foundation slab was considered in the numerical analysis. The outer diameter of the concrete tank is $41 \mathrm{~m}$, its height is $25 \mathrm{~m}$, and the wall thickness is $0.6 \mathrm{~m}$. The reinforced concrete roof is $5.8 \mathrm{~m}$ high and $0.4 \mathrm{~m}$ thick. The concrete which was used to build this LNG tank is grade C40, which had a compressive strength of $40 \mathrm{MPa}$ and a unit weight of $26.40 \mathrm{kN} / \mathrm{m}^{3}$. Additionally, the ordinary reinforcing steel with the yield strength of $400 \mathrm{MPa}$, the ultimate tensile strength of $600 \mathrm{MPa}$ which corresponds to the ultimate tensile strain of 0.14 , a modulus of elasticity $2 \times 10^{5} \mathrm{MPa}$ and a unit weight of $78 \mathrm{kN} / \mathrm{m}^{3}$ are used. 
Prestressing tendons were used in the tank wall, which had a yield strength of 1,581 MPa, the ultimate tensile strength of $1,860 \mathrm{MPa}$ corresponding to the ultimate tensile strain of 0.0575 , and a unit weight of $78 \mathrm{kN} / \mathrm{m}^{3}$. The vertical rebars in the tank wall were spaced around the circle every $3^{\circ}$, and the circumferential steel rebars were spaced every $0.6 \mathrm{~m}$ along the tank wall, which are measurements similar to those recommendations found in the existing literature [6].

\section{NUMERICAL MODELLING}

\subsection{General model description}

The finite element software ABAQUS (2018) was used to develop the numerical model for both fixed-base and hinged-base concrete LNG tanks and to perform modal analyses, as well as nonlinear time history analyses. Fig. 2 presents the numerical model of the entire tank. The tank wall, roof and base slab were modelled using 4-noded shell element S4R, while the rebars were defined as layers of uniaxial reinforcement in the shell elements, as recommended by other researchers [11]. The LNG tank model consisted of 11,648 elements that were utilised for this analyses.

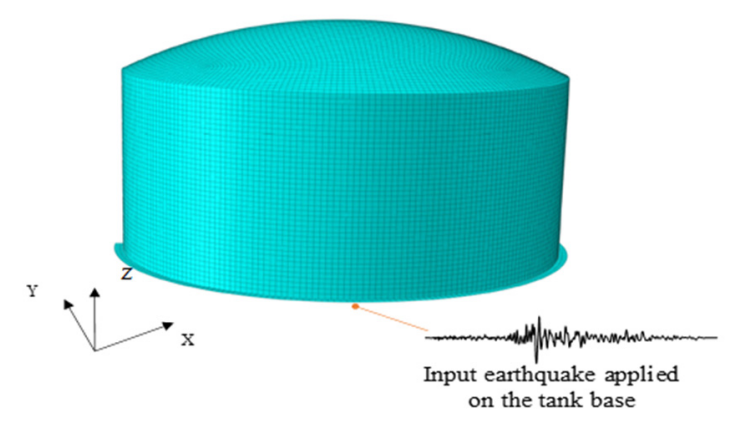

Figure 2: 3D numerical model of the concrete liquid natural gas tank.

\subsection{Adopted material model for reinforced concrete}

To represent the elasto-plastic behaviour of the concrete tank under seismic loads, the concrete damage plasticity (CDP) model was used in this study. This constitutive model, available in ABAQUS, considers two failure mechanisms for the concrete: tensile cracking and compressive crushing [7]. Under the uniaxial tension, the stress-strain relationship follows the linear elastic behaviour until the failure stress $\sigma_{t o}$ is reached, beyond which cracks are generated in the concrete that lead to softening of the stress-strain response of the concrete.

Degradation of the elastic stiffness is considered by means of two damage variables, named $d_{t}$ and $d_{c}$, for tension and compression respectively, which are assumed to be functions of the plastic strains. These damage variables represent the stiffness recovery after the cracks are generated in the concrete material, which is very important for the mechanical response of the concrete that was subjected to cyclic loading, such as seismic loads [8].

The experimental observations that are available in the literature show that when the load changes from tension to compression in concrete, the compressive stiffness recovers, as the 
cracks close under compression [7], while the tensile stiffness does not recover after the crushing, as micro-cracks develop. Stiffness recovery variables can take a value between 1 and 0 , representing a full recovery and total loss of the stiffness, respectively. The CDP model represents the elasto-plastic behaviour of the plain concrete, while the effects associated with the reinforcements, as the bond slip and dowel action, were modelled by the introduction of tension stiffening, to include the load transfer process through the cracks by the rebars. As mentioned earlier, the rebars were modelled using layers of uniaxial reinforcement in the shell elements, for both the vertical and circumferential directions.

Table 1 summarises the essential constitutive parameters for the concrete $\mathrm{C} 40$ used in this study, while Fig. 3 presents the uniaxial compression and tension stress-strain curves of the concrete that were obtained from existing literature [7]-[11]. For the rebars, the Mises yield criterion in combination with the kinematic hardening law was used with the material characteristics mentioned previously.

Table 1: Adopted parameters for simulation of concrete reactivity in this study.

\begin{tabular}{|l|c|c|c|}
\hline Parameter name & Symbol & Value & Reference \\
\hline Dilation angle & $\psi$ & $36^{\circ}$ & \multirow{2}{*}[9]{} \\
\hline Eccentricity & $\epsilon$ & 0.1 & \\
\hline Biaxial/uniaxial compressive yield strength ratio & $f_{b 0} / f_{c 0}$ & 1.16 & {$[7]$} \\
\cline { 1 - 3 } Hydrostatic effective stress ratio & $K$ & 0.667 & \multirow{2}{*}[11]{} \\
\cline { 1 - 2 } Compressive stiffness recovery parameter & $W_{c}$ & 1 & \\
\cline { 1 - 3 } Compressive stiffness recovery parameter & $W_{t}$ & 0 & \\
\hline
\end{tabular}

a) Compression.
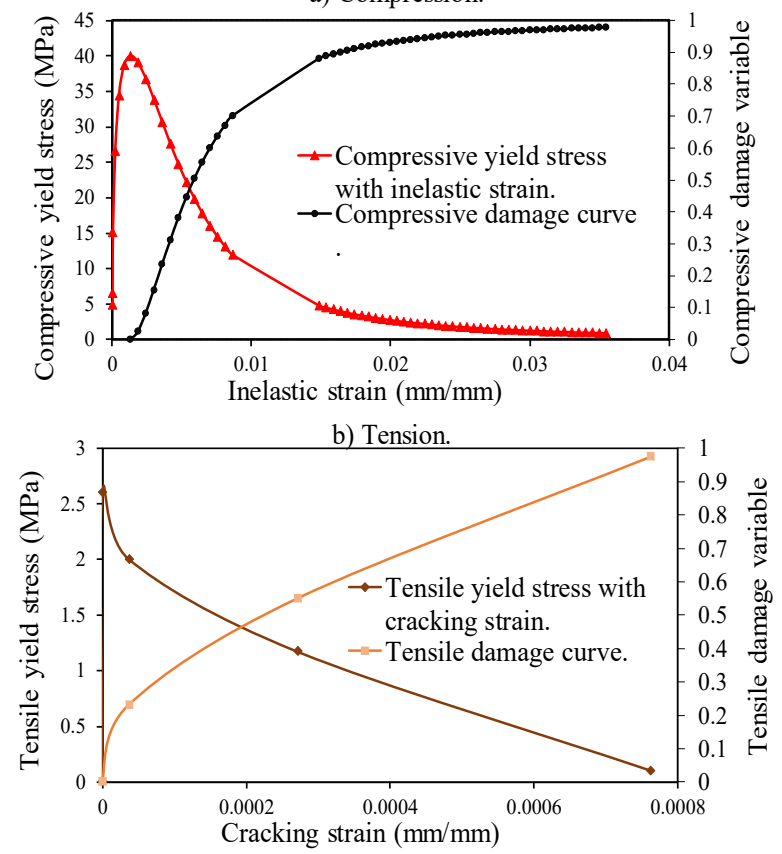

Figure 3: Uniaxial stress-strain curves for concrete and the damage variables with strain, for concrete C40. (a) Compression; and (b) Tension. 


\subsection{Connection details and earthquakes chosen}

The conducted analyses included two parts, the modal analysis and the time history analysis. According to ACI 350.3-06 [10], the wall-base connection of the ground-supported tanks can be classified as being under a fixed-base or hinged-base support condition. For the fixed-base condition (which can come in two forms, as seen in Fig. 4(a)), no rotation nor relative movement are allowed at the connection of the wall to the base, and the vertical reinforcements connect the wall with the foundation, and extend across the joints, to resist the bending moment at the tank base. For the fixed-base arrangement with a closure strip used instead of the vertical reinforcement, the tank wall is connected via the closure strip to the foundation, to overcome potential concrete shrinkage issues [11]. For the hinged-base connection (which also comes in two forms, as shown in Fig. 4(b)), rotation is allowed and thus, no considerable bending moment can be transmitted between the tank wall and the base.
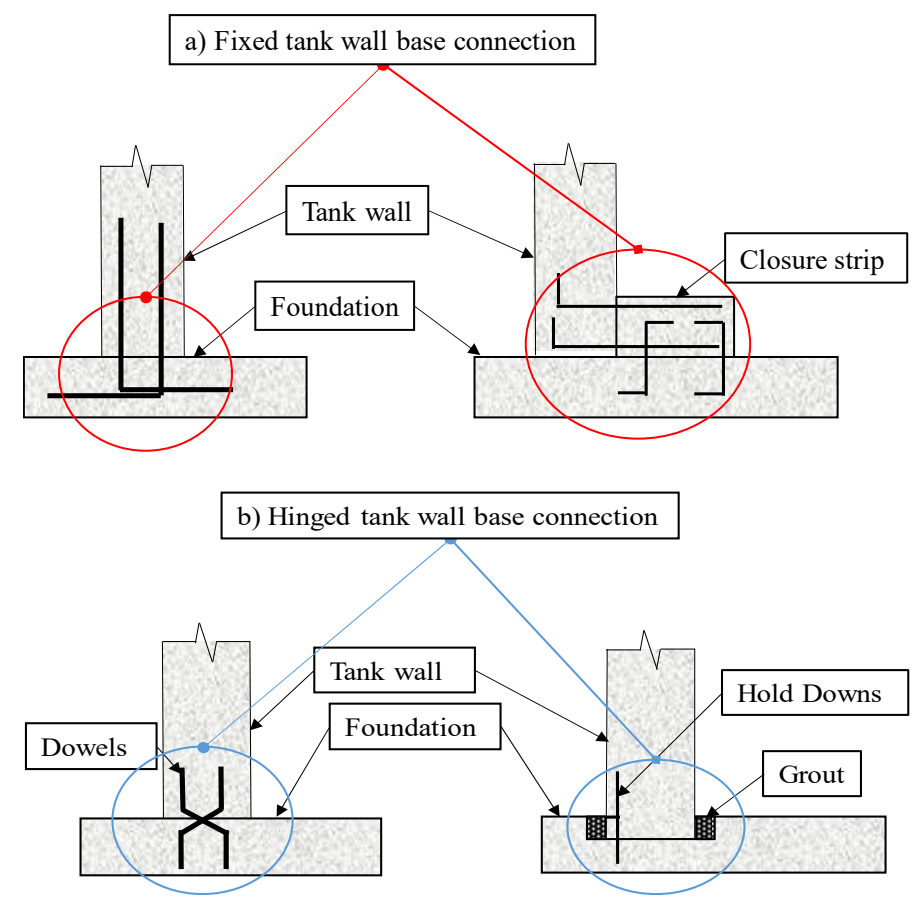

Figure 4: Ground-supported tank support connections. (a) Fixed base conditions; and (b) Hinged base conditions, based on ACI 350.3-06 [10].

The modal analyses were conducted to obtain the natural frequencies of the tank, using the Block Lanczos algorithm, and the details of the mode shapes were captured. After establishing the initial equilibrium under the gravity loading; earthquake excitations, namely the 1995 Kobe earthquake (Fig 5(a)) and the 1994 Northridge earthquake (Fig. 5(b)) [12], were applied to the model in time history analyses, assuming that the LNG tank was sitting on a hard rock site. No vertical ground motions were considered. 

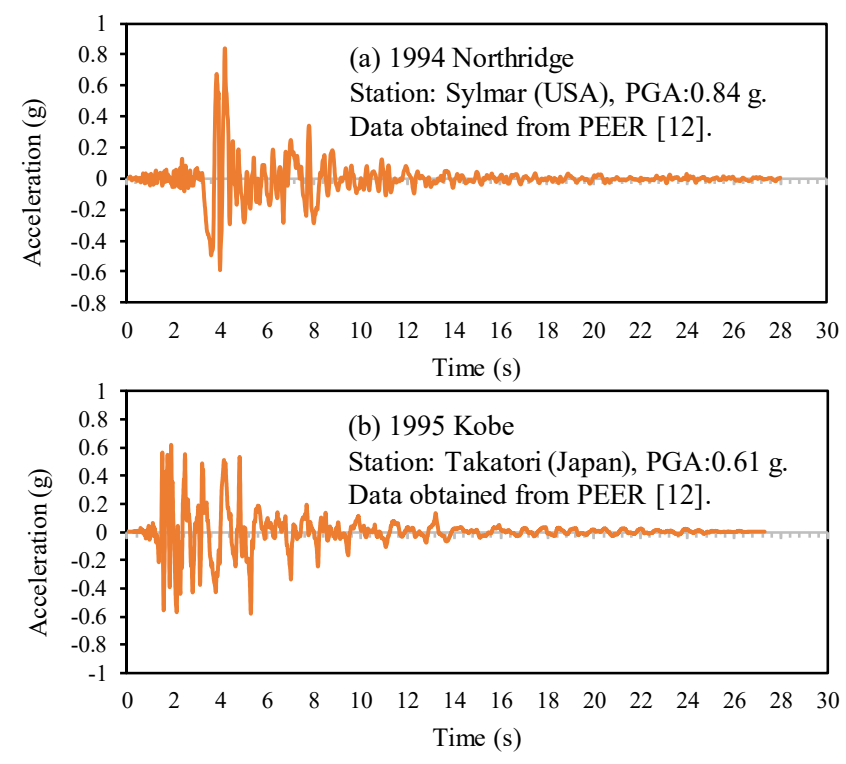

Figure 5: Adopted earthquake time histories of the ground accelerations. (a) 1994 Northridge earthquake; (b) 1995 Kobe earthquake.

\section{RESULTS AND DISCUSSION}

\subsection{Modal analysis}

A modal analysis was conducted for the empty reinforced concrete tanks with two wall foundation conditions, i.e. fixed-base and hinged-base conditions, using the Block Lanczos algorithm. The natural frequencies and periods for the first mode of vibration for the tanks are summarised in Table 2. As expected, the natural period for the hinged base concrete LNG tank is slightly larger than the fixed base, due to a reduction in stiffness and the ability of tank wall to rotate around the foundation slab.

Table 2: Fundamental vibration period of the fixed-base and hinged-base tank conditions.

\begin{tabular}{|c|c|c|}
\hline Tank base condition & $\begin{array}{c}\text { Fundamental natural } \\
\text { frequency }(\mathrm{Hz})^{*}\end{array}$ & $\begin{array}{c}\text { Fundamental natural } \\
\text { period }(\mathrm{s})\end{array}$ \\
\hline Fixed base & $10.2(m=1, n=4)$ & 0.098 \\
Hinged base & $8.8(m=1, n=5)$ & 0.12 \\
\hline
\end{tabular}

As the shell wall of the cylindrical tanks can vibrate in two directions of the cylindrical coordinates; i.e. the circumferential (defined by circumferential wave number $n$ ) and axial direction (defined by the axial wave number $m$ ), the fundamental mode shape for both tanks was extracted and reported in Fig. 6. The first fundamental mode captures wall deformation in the radial direction of the cylindrical coordinates; while no major deformation occurred on the tank roof, under both fixed-base (Fig. 6(a)) and hinged-base (Fig. 6(b)) conditions. The circumferential wave numbers were $n=4$ for the fixed base and $n=5$ for the hinged-base conditions, while the axial wave number was $m=1$ under both conditions. 
(a) Fixed base tank.

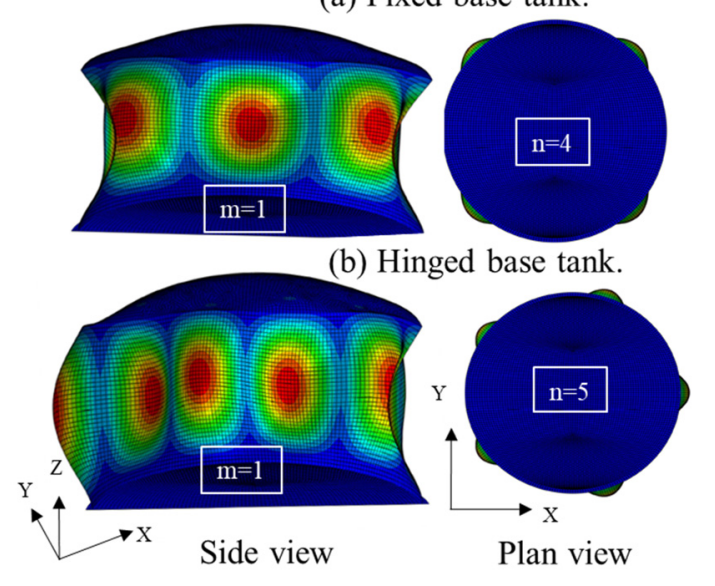

Figure 6: The fundamental mode shape. (a) Fixed-base tank; and (b) Hinged-base tank.

\subsection{Non-linear dynamic time history analyses}

Non-linear dynamic time history analyses were performed on the concrete LNG tanks with different base conditions. As explained earlier, two large bedrock earthquake time-histories, namely the 1994 Northridge and 1995 Kobe earthquakes, were applied. Fig. 7 shows the response spectrums of these earthquakes. Assuming that the LNG tank was sitting on a hard rock site, these earthquakes were applied to the base of the model in the horizontal direction: the predicted structural responses of the tanks are summarised in Table 3.

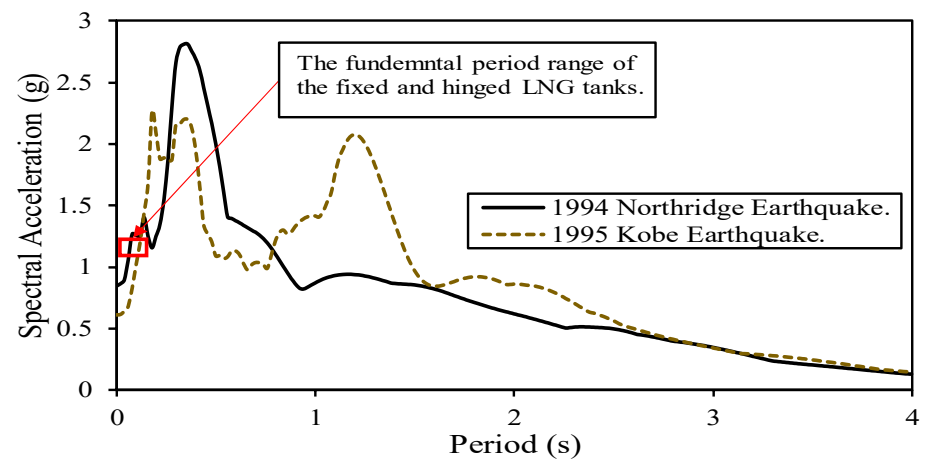

Figure 7: Acceleration response spectra for the selected earthquakes.

The tanks' structural responses to the earthquake models are presented in Table 3, which are reported at the locations with the maximum response within the tank wall. The Hoop force and bending moment were considered as per circumferential unit width of the wall. Figs 9-11 show the values of the hoop forces, bending moments and radial displacements along the wall height (along Section A-A, in Fig. 8) for either the fixed or hinged tanks, due to 1994 Northridge and 1995 Kobe earthquakes, respectively. 
Table 3: Structural response of the tanks with the fixed and hinged base conditions.

\begin{tabular}{lccccc}
\hline Earthquake & $\begin{array}{c}\text { Tank base } \\
\text { condition }\end{array}$ & $\begin{array}{c}\text { Base shear } \\
\text { force (MN) }\end{array}$ & $\begin{array}{c}\text { Hoop force } \\
\text { atop the tank } \\
\text { wall }(\mathrm{MN} / \mathrm{m})\end{array}$ & $\begin{array}{c}\text { Bending moment } \\
\text { atop tank wall } \\
(\mathrm{kN} . \mathrm{m} / \mathrm{m})\end{array}$ & $\begin{array}{c}\text { Radial } \\
\text { displacement } \\
\text { atop tank } \\
\text { wall }(\mathrm{mm})\end{array}$ \\
\hline \multirow{2}{1}{$\begin{array}{c}\text { N94 } \\
\text { Northridge }\end{array}$} & Hixed & 72.6 & 0.8 & 65.9 & 9.7 \\
\hline \multirow{2}{*}{1995 Kobe } & Fixed & 83.6 & 1.17 & 138 & 13.3 \\
\cline { 2 - 6 } & Hinged & 59.2 & 1.65 & 47.9 & 3.7 \\
\hline
\end{tabular}

(a) Section A-A side view

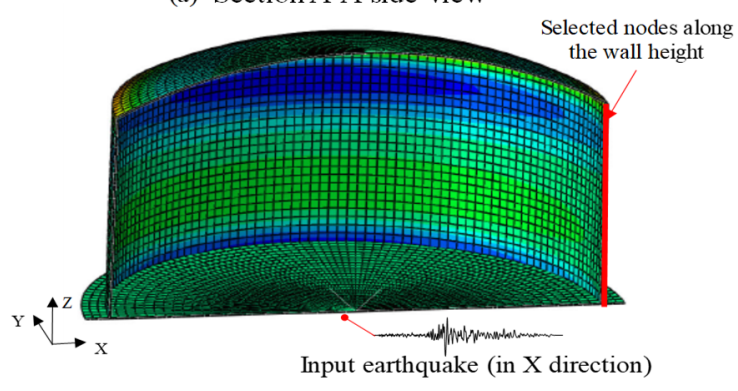

(b) Section A-A plan view

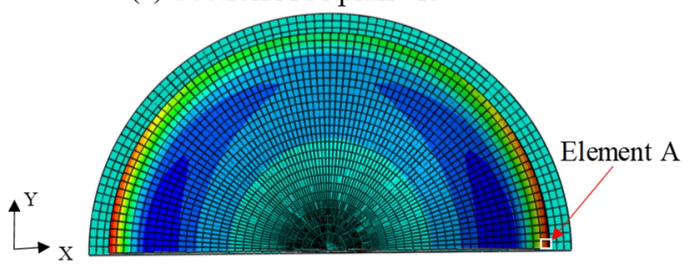

Figure 8: Section A-A of the tank. (a) Side view; and (b) Plan view.

Referring to Table 3 and Fig. 7, the base shear force occurred at the base of the hingedbase tank is larger than the fixed-base tank, as the shear force increased from 72.6 MN to 83.6 MN under a simulated 1994 Northridge earthquake model using the horizontal direction data; and from 48.2 MN to 59.8 MN under a simulated 1995 Kobe earthquake model (i.e. $24 \%$ more); as the natural period increased for the hinged-base tank compared with the fixedbase tank in a short period, which caused increased base shear force to the hinged-base tank.

Fig. 9 shows the hoop forces for the fixed-base and hinged-base tanks along the height of the tank wall, due to the 1994 Northridge (Fig. 9(a)) and 1995 Kobe (Fig. 9(b)) earthquakes. In general, the maximum hoop forces occurred at the top of the tank wall, while the hingedbase tank experienced higher hoop force at the wall top, when compared with the fixed-base tank. Indeed, the maximum hoop forces increased for the fixed-base tank to the hinged-base tank, by $46 \%$ for the 1994 Northridge and $48 \%$ for the 1995 Kobe earthquakes. This observation is related to the fixed-roof effect on the hoop forces; as the roof exerts more hoop force for a hinged-base tank, compared with a fixed-base tank; because of the reduction of the lateral stiffness at the tank base. 
a) 1994 Northridge Earthquake.

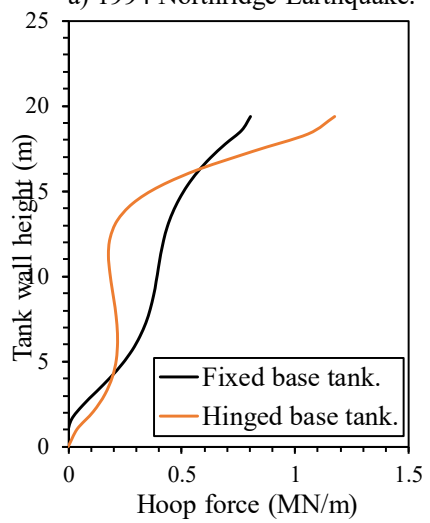

b) 1995 Kobe Earthquake.

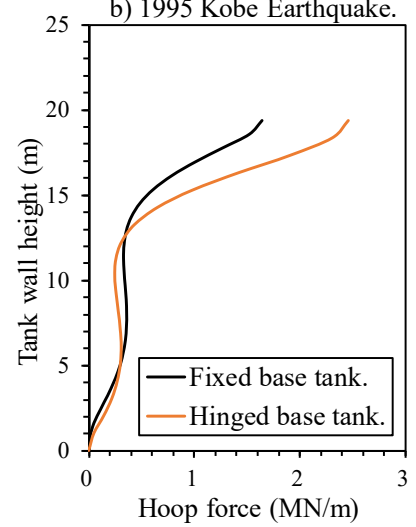

Figure 9: Distribution of hoop force along the height of the tanks' wall along Section A-A, when the maximum hoop force was observed for the (a) 1994 Northridge earthquake; and (b) 1995 Kobe earthquake.

On the other hand, Fig. 10 represents the bending moment for the fixed-base and hingedbase conditions along the height of the tank wall, due to the horizontal effects of the simulated 1994 Northridge (Fig. 10(a)) and 1995 Kobe (Fig. 10(b)) earthquakes. For the hinged-base condition, as expected, the bending moment is zero at the wall base for both earthquakes, while the corresponding bending moments at the base for the fixed base condition are $68.7 \mathrm{kN} . \mathrm{m} / \mathrm{m}$ under the 1994 Northridge earthquake and $51.4 \mathrm{kN} . \mathrm{m} / \mathrm{m}$ under 1995 Kobe earthquake conditions; however, the hinged-base tank did experience more bending moment for the upper part of the tank wall, compared with the fixed-base tank. In general, more contributions to higher structural modes are observed in the hinged-base tank, when compared with the fixed-base tank.

a) 1994 Northridge Earthquake.
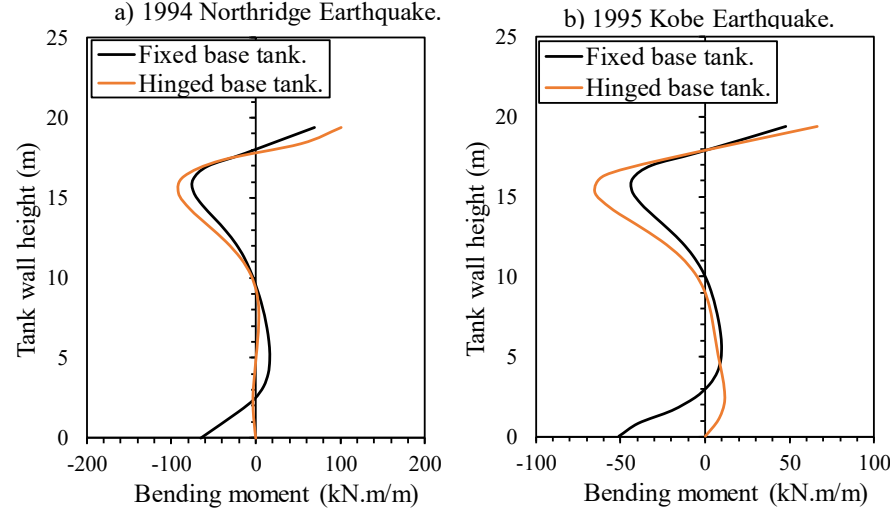

Figure 10: Distribution of the bending moments along the height of the tanks' wall along Section A-A, when the maximum bending moment was observed for these simulated earthquakes. (a) 1994 Northridge; and (b) 1995 Kobe. 
In addition, as shown in Fig. 11 the radial displacements under the fixed-base and hingedbase tank conditions in the 1994 Northridge (Fig. 11(a)) and 1995 Kobe (Fig. 11(b)) earthquakes. As the hinged-base tank has the ability to rotate in a radial direction, the radial/lateral displacements on the hinged-base tank were found to be more than the fixedbase tank, when subjected to both earthquake conditions. Fig. 11 shows the maximum lateral displacements which occurred at the wall-roof connection, which were $13.3 \mathrm{~mm}$ and $4.6 \mathrm{~mm}$ for the hinged-base tank when subjected to the 1994 Northridge and 1995 Kobe earthquakes, respectively. The corresponding values for the fixed-base tank were $9.7 \mathrm{~mm}$ and $3.7 \mathrm{~mm}$.

a) 1994 Northridge Earthquake.

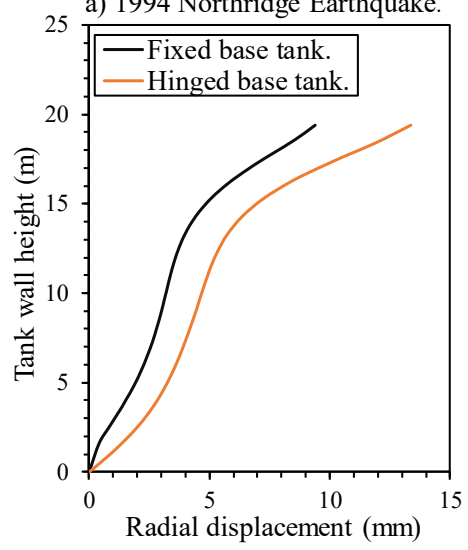

b) 1995 Kobe Earthquake.

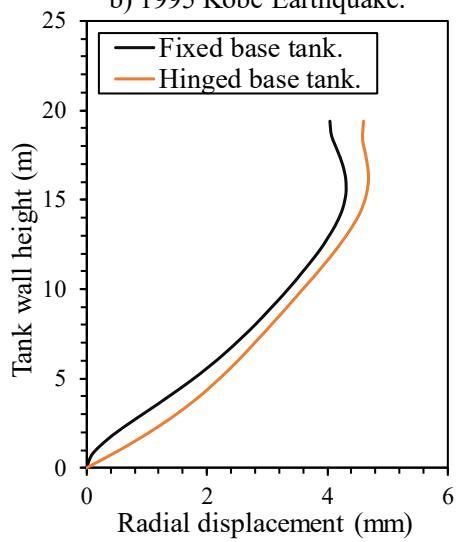

Figure 11: Distribution of radial displacements along the height of the tank wall along Section A-A, where radial displacement was observed in the model under earthquake conditions. (a) 1994 Northridge; and (b) 1995 Kobe.

To evaluate the damage of the LNG concrete tanks under large earthquakes, the strain time history for a selected element (i.e. Element A as shown in Fig. 8(b)) which experienced tensile damage is compared. Fig. 12(a) shows the strain time history of Element A (the wallroof joint) under the fixed- and hinged-base conditions in a simulated 1994 Northridge earthquake. It was evident that the strain increased to $0.005 \%$, due to the dead load, and then started to oscillate around this value during the 1994 Northridge earthquake excitation. Indeed, Element A constantly experienced tension (as the strain was mostly kept above zero), which means that compressive damage was not observed. Then, at about $t=5 \mathrm{~s}$, when the peak acceleration ( $\mathrm{PGA}=0.84 \mathrm{~g}$ ) occurred, the strain increased considerably to $0.016 \%$, well exceeding the cracking strain of $0.0087 \%$. However, we found that the strain time history for the fixed-base condition oscillated around the initial strain due to self-weight, while the maximum strain was $0.013 \%$ at $t=5 \mathrm{~s}$.

In general, the Element $\mathrm{A}$ in a hinged-base tank experienced higher strains, as compared with the fixed-base counterpart, under both earthquake simulations (Fig. 12(a) and 12(b)). The maximum predicted tensile strain for the hinged-base condition under the 1995 Kobe earthquake was $0.013 \%$, while the corresponding value for the fixed-base counterpart was $0.011 \%$ (i.e. $20 \%$ more). This observation was in line with the structural response reported in Fig. 11, where more displacements were induced in the hinged-base tank wall, as compared with the fixed-based tank wall, creating more strain and thus, damage to the wall-roof joint in the hinged-base tank. 
a) 1994 Northridge Earthquake.

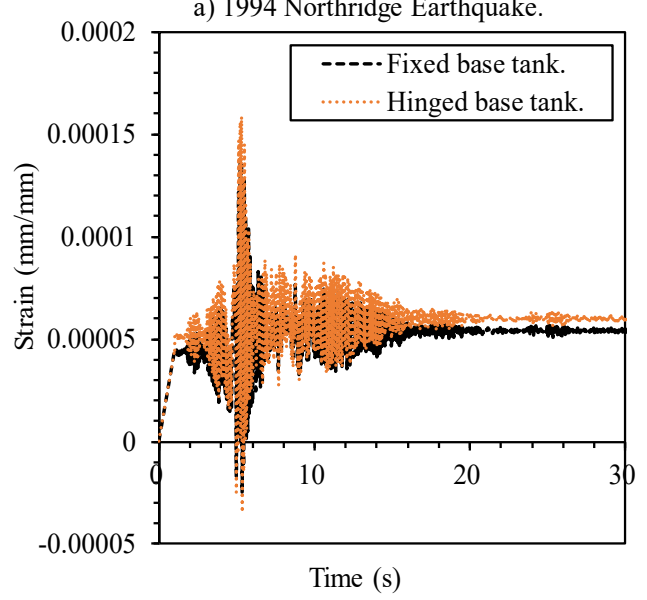

b)1995 Kobe Earthquake.

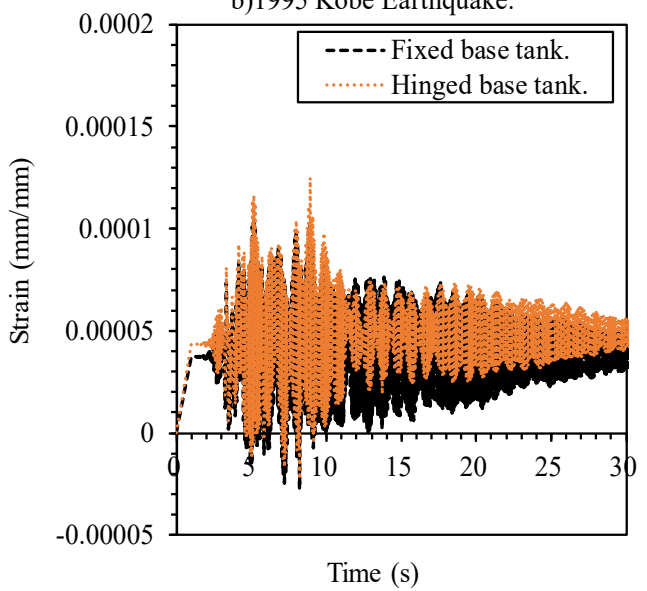

Figure 12: Strain time histories for the fixed-base and hinged-base tank walls at Element A (the wall-roof joint), for earthquakes. (a) 1994 Northridge; and (b) 1995 Kobe.

(a) 1994 Northridge Earthquake

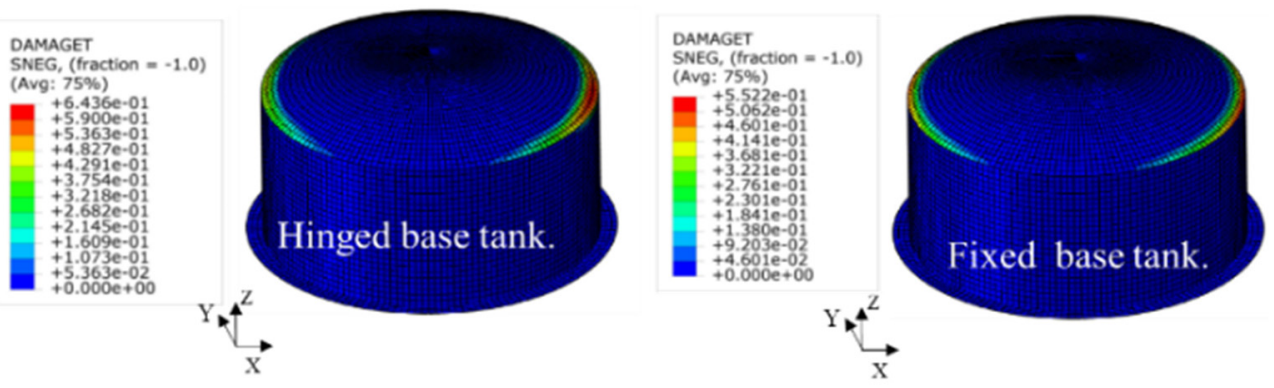

(b) 1995 Kobe Earthquake

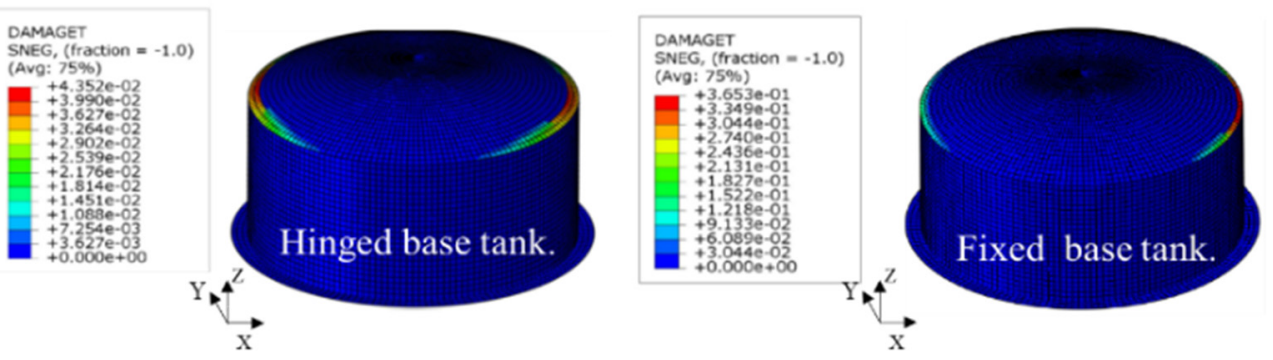

Figure 13: Maps of the damage and stiffness degradation in hinged- and fixed-base tanks under earthquake conditions. (a) 1994 Northridge; and (b) 1995 Kobe. 
The tensile damage parameter for the fixed-base and hinged-base types of LNG tanks under the 1994 Northridge and 1995 Kobe earthquake conditions were extracted (Fig. 13). The pattern of damage, with the estimation of stiffness degradation, are illustrated for both the hinged- and fixed-base tanks when under 1994 Northridge earthquake (Fig. 13(a)) and under 1995 Kobe earthquake conditions (Fig. 13(b)). The tensile damage variable due to cracking, as it characterises the stiffness degradation of the concrete, takes values ranging from zero (undamaged material) to one (total loss of stiffness). Fig. 13 proved that the tensile stiffness reduction in the hinged-base tank reached $64 \%$, while for the fixed-base tank it reached 55\%, under the 1994 Northridge earthquake conditions. Stiffness reduction for the hinged- and fixed-base tanks under 1995 Kobe earthquake conditions were 43\% and 36\%, respectively. Indeed, cracks were generated in the tank roof only; which has less section thickness, compared with the top of the tank wall. These predicted stiffness degradation and damage variations are in line with the strain variations that were reported in Fig. 12.

\section{CONCLUSIONS}

This paper investigated the effects of the type of wall to base slab connection (i.e. hinged or fixed) on the nonlinear seismic response of a reinforced concrete LNG tank, $41 \mathrm{~m}$ in diameter and $25 \mathrm{~m}$ in height. To capture the inelastic behaviour of the tank, the concrete damage plasticity (CDP) model was adopted, which could capture the permanent damage to the concrete tank during a seismic excitation. Modal and time history analyses were conducted. The results showed that the hinged-base tank experienced slightly higher base shear forces, and higher radial/lateral displacements, which resulted in significant tensile damage, cracking and stiffness degradation for the concrete hinged tank under conditions found in the 1994 Northridge and 1995 Kobe earthquakes. While the fixed-base tank experienced higher bending moment at the tank base, compared with the hinged base tank; nevertheless, no damage was observed at the wall-base connection. It can be concluded that adding structural flexibility at the tank base can potentially lead to higher seismic forces on a tank wall, and more damage particularly to large containment tanks subjected to large earthquakes. This means that for hinged-base tanks, the roof needs to be strengthened by increasing the reinforcement, to prevent any damage.

Because the natural period of the tanks is located in the short-period range of the response spectrum of applied earthquakes, lengthening the period as a result of hinging the wall-tobase connection would result in more base shear force being transferred to the LNG concrete tank. Indeed, for building structures with a high natural frequency (or low natural period), providing more flexibility can lead to reduction in the seismic demand.

\section{REFERENCES}

[1] Khansefid, A., Maghsoudi-Barmi, A. \& Khaloo, A., Seismic protection of LNG tanks with reliability based optimally designed combined rubber isolator and friction damper. Earthquakes and Structures, 16, pp. 523-532, 2019.

[2] Zhai, X., Zhao, X. \& Wang, Y., Numerical modeling and dynamic response of $160,000 \mathrm{~m}^{3}$ liquefied natural gas outer tank under aircraft impact, Journal of Performance of Constructed Facilities, 33, p. 04019039, 2019.

[3] Graczyk, M. \& Moan, T., A probabilistic assessment of design sloshing pressure time histories in LNG tanks. Ocean Engineering, 35, pp. 834-855, 2008.

[4] Christovasilis, I.P. \& Whittaker, A.S., Seismic analysis of conventional and isolated LNG tanks using mechanical analogs. Earthquake Spectra, 24, pp. 599-616, 2008. 
[5] Lee, S.W., Choi, S.J. \& Kim, J.-H.J., Analytical study of failure damage to 270,000-kL LNG storage tank under blast loading. Computers and Concrete, 17, pp. 201-214, 2016.

[6] Shu, L., Gu, H., Shi, G., You, Y. \& Zhen, J., Design and construction technique of large LNG PC tank. Industrial Buildings, 11, pp. 32-44, 2007.

[7] Lee, J. \& Fenves, G.L., Plastic-damage model for cyclic loading of concrete structures. Journal of Engineering Mechanics, 124, pp. 892-900, 1998.

[8] Saenz, L., Equation for the stress-strain curve of concrete in uniaxial and biaxial compression of concrete. ACI Journal, 61, pp. 1229-1235, 1965.

[9] Nayal, R. \& Rasheed, H.A., Tension stiffening model for concrete beams reinforced with steel and FRP bars. Journal of Materials in Civil Engineering, 18, pp. 831-841, 2006.

[10] American Concrete Institute Committee 350.3-06, Seismic design of liquid-containing concrete structures and commentary. American Concrete Institute: Farmington Hills, MI, 2006.

[11] Hafez, A., Seismic response of ground-supported circular concrete tanks. $\mathrm{PhD}$ thesis, Toronto, Canada, 2012.

[12] Pacific Earthquake Engineering Research Center, PEER ground motion database. University of California, Berkeley, CA. http://ngawest2. 